\title{
Recovery plug for HeartMate 3 left ventricular assist device
}

\author{
Johanna Mulzer, MD, ${ }^{\mathrm{a}}$ Gloria Faerber, MD, ${ }^{\mathrm{b}}$ Friedrich Kaufmann, DiplEng, ${ }^{\mathrm{a}}$ and
}

Evgenij V. Potapov, MD, PhD, ${ }^{\mathrm{a}, \mathrm{c}}$ Berlin and Jena, Germany

\footnotetext{
From the ${ }^{\mathrm{a}}$ Department of Cardiothoracic and Vascular Surgery, German Heart Center Berlin, Berlin, Germany ${ }^{\mathrm{b}}$ Department of Cardiothoracic Surgery, Universitätsklinikum Jena, Jena, Germany; and ${ }^{\mathrm{c} D Z H K}$ (German Center for Cardiovascular Research), Partner Site Berlin, Berlin, Germany.

No funding was provided.

Disclosures: Authors have nothing to disclose with regard to commercial support.

Received for publication May 2, 2018; revisions received June 22, 2018; accepted for publication July 2, 2018; available ahead of print Sept 1, 2018.

Address for reprints: Johanna Mulzer, MD, Department of Cardiothoracic and Vascular Surgery, German Heart Center Berlin, Augustenburger Platz 1, 13353 Berlin, Germany (E-mail: mulzer@dhzb.de).

J Thorac Cardiovasc Surg 2019;157:e35-7

$0022-5223 / \$ 36.00$

Copyright (C) 2018 Published by Elsevier Inc. on behalf of The American Association for Thoracic Surgery https://doi.org/10.1016/j.jtcvs.2018.07.041
}

Video clip is available online.

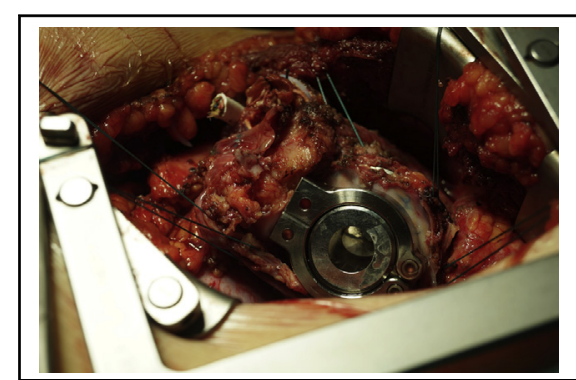

The recovery plug in situ.

Central Message

We describe the first clinical use of a customized recovery plug in 3 patients with myocardial recovery after HeartMate 3 implantation.

See Editorial Commentary page e39.
Myocardial recovery in women with postpartum cardiomyopathy supported with a left ventricular assist device (LVAD) has been described. ${ }^{1}$ In selected cases LVAD explantation was possible.

The most elegant way to explant an LVAD for myocardial recovery is by using a specially designed "recovery plug," which was introduced into clinical practice in 2009 for the HeartMate II (Abbott Medical, Abbott Park, Ill) and the HeartWare HVAD (Medtronic, Minneapolis, Minn). ${ }^{2}$ The HeartMate 3 LVAD (Abbott Medical) is a new pump that received the CE Mark in 2015 and US Food and Drug Administration approval in 2017. The unique pump fixation ring of the HeartMate 3 requires a novel design to ensure secure and leakproof fitting after explantation.

We describe the first clinical use of a customized recovery plug in 3 cases.

\section{CLINICAL SUMMARIES}

The first patient was an 18-year-old woman who came to the German Heart Center Berlin with heart failure symptoms after the delivery of a healthy child. A HeartMate 3 LVAD was implanted.

Ten months later, she was seen in the outpatient department with a driveline infection. Echocardiography showed normal function of the heart. In accordance with our weaning protocol, ${ }^{3,4}$ pump explantation was scheduled. The pump was exposed through a left anterior thoracotomy in the sixth intercostal space. Cardiopulmonary bypass
(CPB) was installed through left groin vessels for safety reasons. The kinking protector was opened, and the graft was ligated and dissected, as was the driveline close to the pump. The outflow graft, pump, and intrathoracic part of the cable seemed not to be infected. In this situation, we decided to use the customized plug. The closing mechanism was opened, and the pump was removed. Inspection of the left ventricle detected no thrombi. The plug was therefore inserted and secured (Figure 1 and Video 1).

A similar case of postpartum cardiomyopathy in a 22year-old woman was treated in Jena, Germany. The woman had been on HeartMate 3 support for 582 days and demonstrated sustained myocardial recovery, as proved by functional testing. Echocardiography performed with reduced pump speed showed good myocardial function but moderate mitral insufficiency. The HeartMate 3 was therefore explanted through a resternotomy with the customized plug during CBP while the mitral valve was also repaired. The postoperative course was uneventful.

Recently, a 55-year-old-man with dilative cardiomyopathy supported for 193 days had successful HeartMate 3 explantation in Berlin by means of an off-pump-technique with the same strategy and device.

The recovery plug (Fittkau Metallbau GmbH, Berlin, Germany) is made of titanium and consists of 3 parts (Figures 2 and 3). The plug itself is sintered with titanium spheres and has two mobile wings, forming a 


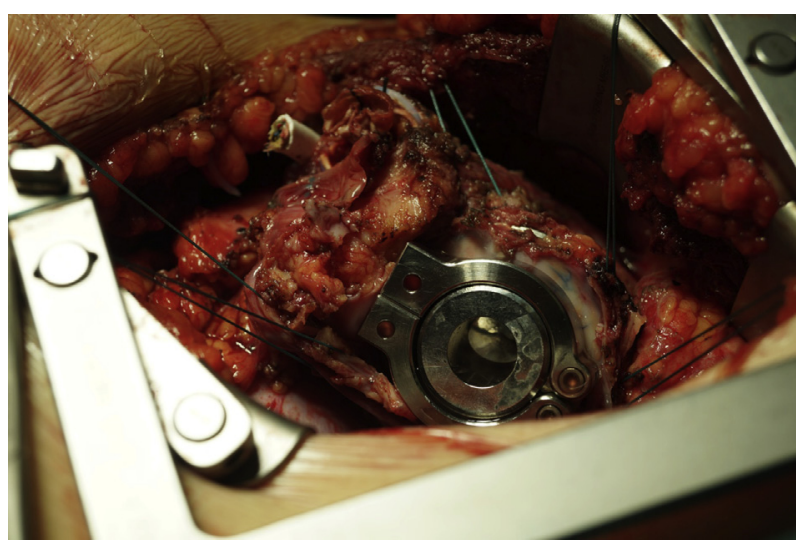

FIGURE 1. The plug in situ.

circumferential safety catch to secure the plug in the sewing ring. After pump removal and insertion of the plug into the left ventricle, the wings are closed and screwed together with a screw integrated into one of the wings. The tightened wings press the plug onto the silicone covered part of the fixation ring and close it hermetically.

\section{DISCUSSION}

So far more than 3000 HeartMate 3 pumps have been implanted worldwide.

When myocardial recovery occurs, there are several options:

1. Complete removal includes the pump, fixation ring, outflow graft and driveline. This option requires oversewing of the apex of the left ventricle and of the anastomosis to the aorta under CPB.

2. Partial removal encompasses the pump and complete driveline being retrieved through a small incision above the pump in the sixth intercostal space. Because of the oversewing of the apex, this approach also requires CPB.

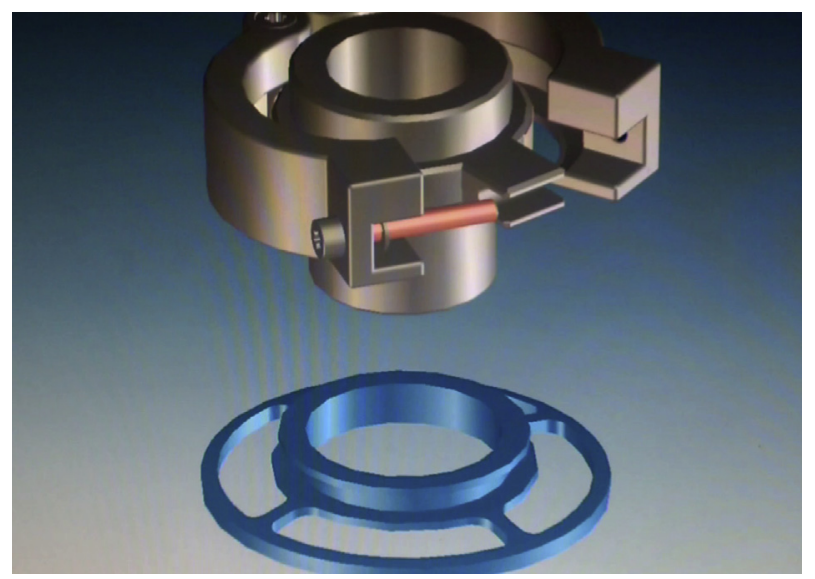

VIDEO 1. The plug in motion. Video available at: https://www.jtcvs.org/ article/S0022-5223(18)32019-1/fulltext.

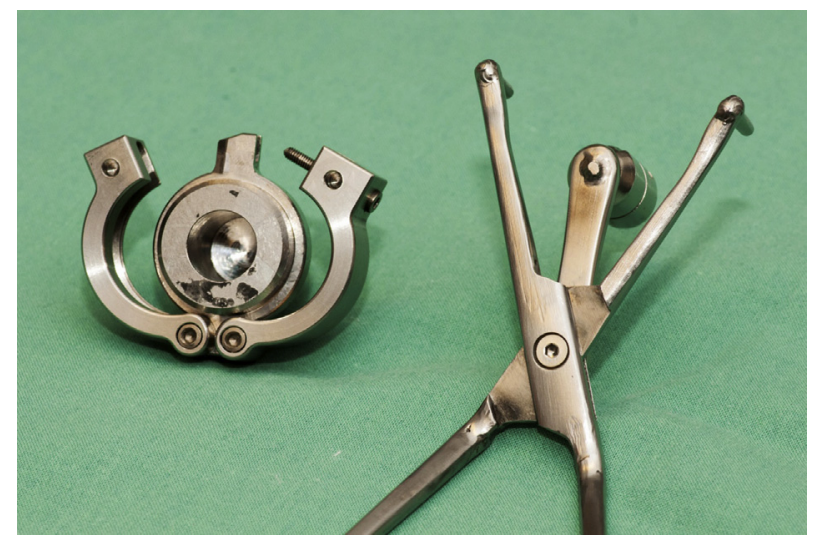

FIGURE 2. The plug and the special clamp designed for simplifying plug insertion.

3. A specially designed titanium plug allows complete removal from the left ventricle and enables the myocardium in the apical area to be preserved and CPB use to be avoided.

4. Percutaneous interventional ligation of the outflow graft can be performed through a small subcostal incision to stop backflow, with transection of the driveline below the skin while the outflow graft, pump and driveline remain in situ.
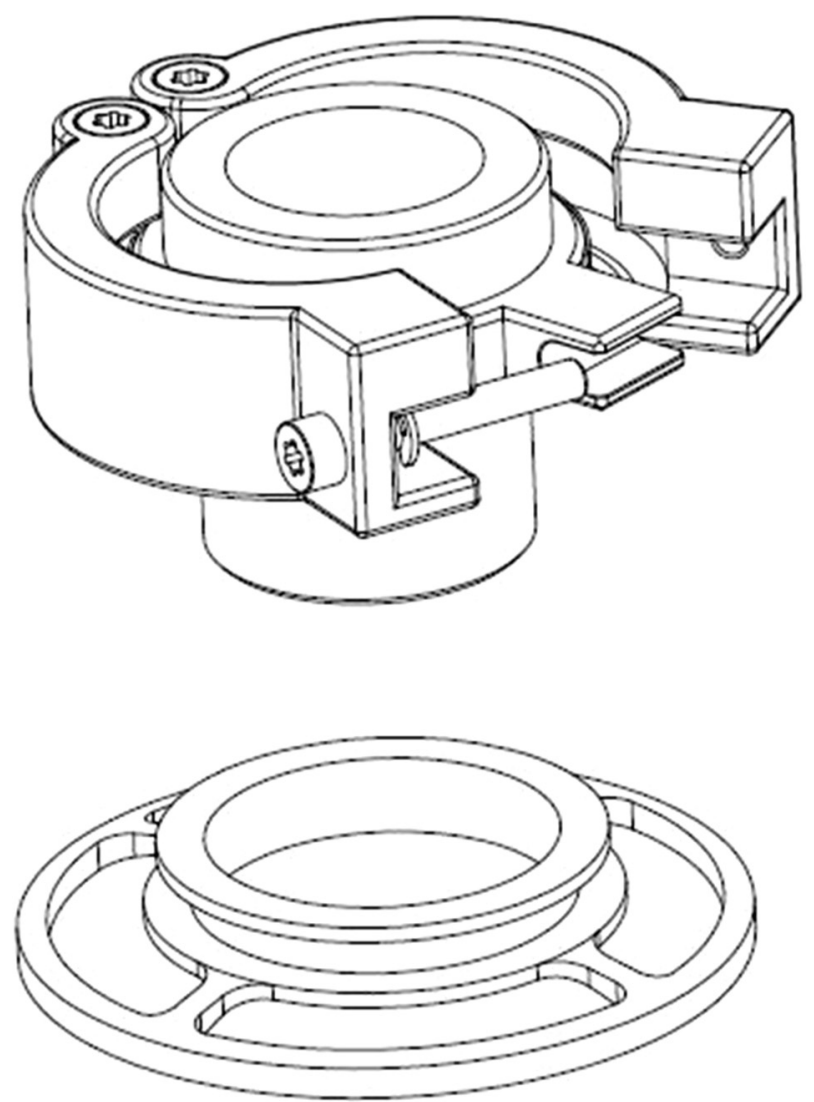

FIGURE 3. Drawing of the plug. 
We chose the third option in the 3 cases presented here, with the customized plug being used for the first time in patients with HeartMate 3. They had an uneventful recovery and are well later.

Six months after explantation, echocardiography in all cases showed a left ventricular ejection fraction greater than $50 \%$ with only mild MI occurring in a single case. None of the patients needed to be re-hospitalized. Two of them have been able to return to work.

The titanium plug is sintered with titanium spheres and becomes overgrown with tissue, therefore requiring anticoagulation with a vitamin $\mathrm{K}$ antagonist for 6 months only. If heart failure recurs and an LVAD is needed for the second time, the fixation ring may be reused after removal of the plug. 5
We thank Anne Gale for editorial assistance.

\section{References}

1. Lueck S, Sindermann J, Martens S, Scherer M. Mechanical circulatory support for patients with peripartum cardiomyopathy. Artif Organs. 2016;19: 305-92.

2. Potapov EV, Stepanenko A, Hennig E, Hetzer R, KrabatschT. A titanium plug simplifies left ventricular assist removal after myocardial recovery. J Heart Lung Transplant. 2010;29:1316-7.

3. Dandel M, Weng Y, Siniawski H, Stepanenko A, Krabatsch T, Potapov E, et al. Heart failure reversal by ventricular unloading in patients with chronic cardiomyopathy: criteria for weaning from ventricular assist devices. Eur Heart J. 2011;32: 1148-60.

4. Potapov EV, Schweiger M, Krabatsch T. Percutaneous balloon occlusion of a left ventricular assist device outflow cannula to facilitate evaluation of myocardial recovery. J Heart Lung Transplant. 2011;30:1300-1.

5. Saito T, Potapov E, Dandel M, Hetzer R, Krabatsch T. Reimplantation of left ventricular assist device late after weaning of device using a titanium plug. J Heart Lung Transplant. 2014:33:972-4. 